University of Wollongong

Research Online

Australian Institute for Innovative Materials -

Papers

Australian Institute for Innovative Materials

$1-1-2019$

\title{
Metallic state two-dimensional holey-structured Co3FeN nanosheets as stable and bifunctional electrocatalysts for zinc-air batteries
}

Haipeng Guo

University of Wollongong, haipeng@uow.edu.au

Xuanwen Gao

xuanwen@uow.edu.au

Nengfei Yu

University of Wollongong, nengfei@uow.edu.au

Zhi Zheng

University of Wollongong, zz532@uowmail.edu.au

Wenbin Luo

University of Wollongong, luow@uow.edu.au

See next page for additional authors

Follow this and additional works at: https://ro.uow.edu.au/aiimpapers

Part of the Engineering Commons, and the Physical Sciences and Mathematics Commons

Research Online is the open access institutional repository for the University of Wollongong. For further information contact the UOW Library: research-pubs@uow.edu.au 


\title{
Metallic state two-dimensional holey-structured Co3FeN nanosheets as stable and bifunctional electrocatalysts for zinc-air batteries
}

\begin{abstract}
Exploring economically efficient electrocatalysts with robust bifunctional oxygen conversion catalytic activity and designing appropriate structures are essential to realize ideal zinc-Air batteries with high energy density and long lifespan. Two-dimensional metallic state Co3FeN nanosheets with a holeystructured architecture are designed and shown to exhibit enhanced catalytic properties owing to the complete exposure of the atoms in the large lateral surfaces and in the edges of pore areas, together with the lowest $\mathrm{OH} *$ adsorption energy on exposed surfaces due to bimetallic synergistic effects. Meanwhile, this porous architecture can not only accelerate electron transportation by its metallic state highly oriented crystallized structure, but also facilitate the diffusion of intermediates and gases. These edgeenriched 2D holey Co3FeN nanosheets exhibit enhanced catalytic activity towards reversible oxygen conversion. When employed in zinc-Air batteries, they exhibit a maximum power density of $108 \mathrm{~mW} \mathrm{~cm}-2$ and cycle life up to 900 cycles with a low round-Trip voltage of $0.84 \mathrm{~V}$. The Co3FeN nanosheets maintain a strong stable structure in an oxygen-rich electrochemical environment with a high-orientation crystalline texture during the whole cycling time. This work may provide a promising candidate to promote the further development of zinc-Air batteries.
\end{abstract}

\section{Keywords}

two-dimensional, state, metallic, nanosheets, stable, co3fen, bifunctional, electrocatalysts, zinc-air, batteries, holey-structured

\section{Disciplines}

Engineering | Physical Sciences and Mathematics

\section{Publication Details}

Guo, H., Gao, X., Yu, N., Zheng, Z., Luo, W., Wu, C., Liu, H. \& Wang, J. (2019). Metallic state two-dimensional holey-structured Co3FeN nanosheets as stable and bifunctional electrocatalysts for zinc-air batteries. Journal of Materials Chemistry A, 7 (46), 26549-26556.

\section{Authors}

Haipeng Guo, Xuanwen Gao, Nengfei Yu, Zhi Zheng, Wenbin Luo, Chang Wu, Hua-Kun Liu, and Jiazhao Wang 


\section{ARTICLE}

Cite this: DOI: 10.1039/x0xx00000x

\section{Metallic State Two-dimensional Holey-Structured Co3FeN Nanosheets as Stable and Bifunctional Electrocatalysts for Zinc-Air Batteries}

Received 00th January 2012, Accepted 00th January 2012

DOI: $10.1039 / \mathrm{x} 0 \mathrm{xx} 00000 \mathrm{x}$

www.rsc.org/

\author{
Hai-Peng Guo ${ }^{\mathrm{a}}$, Xuan-Wen Gao ${ }^{\mathrm{a}, \mathrm{b}}$, Neng-Fei Yu${ }^{\mathrm{a}, \mathrm{c}}$, Zhi Zheng ${ }^{\mathrm{a}}$, Wen-Bin Luo ${ }^{\mathrm{a}, \mathrm{b} *}$, \\ Chang $\mathrm{Wu}^{\mathrm{a}}$, Hua-Kun Liu ${ }^{\mathrm{a}}$, Jia-Zhao Wanga*
}

\begin{abstract}
Exploring economically efficient electrocatalysts with robust bifunctional oxygen conversion catalytic activity and designing appropriate structures are essential to realize ideal zinc-air batteries with high energy density and long lifespan. Two-dimensional metallic state $\mathrm{Co}_{3} \mathrm{FeN}$ nanosheets with holey-structured architecture are designed and shown to exhibit enhanced catalytic properties owing to the complete exposure of the atoms in the large lateral surfaces and in the edges of pore areas, together with the lowest $\mathrm{OH}^{*}$ adsorption energy on exposed surfaces from bimetallic synergistic effects. Meanwhile, this porous architecture can not only accelerate electron transportation by its metallic state highly-orientated crystallized structure, but also facilitates the diffusion of intermediates and gases. These edge-enriched 2D holey $\mathrm{Co}_{3} \mathrm{FeN}$ nanosheets exhibit enhanced catalytic activity towards oxygen reversible conversion. When employed in zinc-air battery, it possesses a maximum power density of $108 \mathrm{~mW} \mathrm{~cm}^{-2}$ and cycle life up to 900 cycles with a low round-trip voltage of $0.84 \mathrm{~V}$. The $\mathrm{Co}_{3} \mathrm{FeN}$ nanosheets keep a strong stable structure in an oxygen-rich electrochemical environment with high-orientation crystalline texture during the whole cycling time. This work may provide a promising candidate to promote the further development of zincair batteries.
\end{abstract}

\section{Introduction}

Due to the excessive depletion of fossil fuels, great efforts have been devoted to the development of novel electrochemical energy conversion and storage systems. ${ }^{1-4}$ Zinc-air batteries are attracting much more attention because of their high energy density, low cost due to abundant resources, excellent durability, and environmental friendliness. ${ }^{5-11}$ The activity towards the oxygen conversion reaction and the structure of their electrocatalysts primarily determine their reversible energy conversion efficiency, energy density, and lifespan. Over a long period of research, much effort has thus been made to explore bifunctional electrocatalysts with ideal structure to accelerate the kinetics of the oxygen reduction reaction (ORR) and the oxygen evolution reaction (OER) simultaneously in the discharge and charge processes. ${ }^{12-16}$ Various materials were reported and employed as electrocatalysts for $\mathrm{Zn}$-air batteries, such as noble metals, transition metal oxides or hydroxides, sulfides, carbides, and alloys. ${ }^{17-25}$ Several issues still need to be addressed for these electrocatalysts, such as high cost, sluggish bifunctional catalytic activity, the low electronic conductivity of semiconductors, and chemical instability. ${ }^{26-29}$ For example, several types are not stable in an oxygen-rich electrochemical environment because they suffer from nucleophilic attack by highly-sensitive intermediate radicals. The low electronic conductivity of semiconductors will slow down the reaction kinetics and enlarge the over-potential as well. ${ }^{30-38}$ Metallic transition metal nitride has received tremendous attention owing to its metallic state and robust chemical bonding, so that it exhibits excellent electrical conductivity and catalytic activity, along with high chemical stability. ${ }^{14,37-41}$ In order to further improve the catalytic activity by ultimate exposing high active crystal lattice, a two-dimensional (2D) highly-orientated crystalline structure of bimetallic $\mathrm{Co}_{3} \mathrm{FeN}$ nanosheets was explored in this work by introducing secondary metal species. ${ }^{42}$ Based on the low $\mathrm{OH}^{*}$ absorption energy of the completely exposed large lateral surfaces, it leads to improved catalytic properties in terms of enhanced electrical conductivity by synergistic effects and greater mechanical stability. ${ }^{43-45}$ In addition, the electrocatalyst structure has a direct relationship with the zinc-air battery performance. For example, the conventional nanocrystal electrocatalysts tend to agglomerate and are easily detached from the substrate during long-term cycling. ${ }^{46-48}$ Therefore, an appropriate 
structure with an enormous density of catalytic active sites should be provided for the accommodation of reaction products to ensure the cycling lifespan. Herein, a holey-structured integrated 2D architecture was designed and employed. It has the inherent advantages of numerous active sites based on huge surface areas, and superior gas and electrolyte penetration, particularly under the complex conditions that apply within a three-phase environment of gas, liquid, and solid. $^{33,49-52}$ This structure can also improve the durability by protecting the electrocatalyst from aggregation and peeling off during long-term cycling. When employed as an electrocatalyst for the zincair battery, these 2D holey-structured metallic $\mathrm{Co}_{3} \mathrm{FeN}$ nanosheets exhibit enhanced electrochemical performance, resulting from their excellent electrical conductivity, ideal architecture, and superior bifunctional catalytic activity towards OER and ORR processes. Firstprinciples density functional theory (DFT) calculations were performed as well to evaluate the adsorption energy of $\mathrm{OH}^{*}$, and it was found that $\mathrm{Co}_{3} \mathrm{FeN}$ is more promising than oxide and alloy electrocatalysts in zinc-air batteries.

\section{Results and discussion}

The detailed experimental information is described in the Experimental Section. Silk-like $\mathrm{Co}_{3} \mathrm{Fe}$ layered double hydroxide (LDH) was firstly synthesized through a hydrothermal method. The $2 \mathrm{D} \mathrm{Co} 3 \mathrm{Fe} \mathrm{LDH}$ has a silk-like smooth nanosheet morphology without any obvious defects as shown in Figure S1 in scanning electron microscope (SEM) and transmission electron microscope (TEM) images. After further nitridation treatment, the ultrathin 2D holey $\mathrm{Co}_{3} \mathrm{FeN}$ nanosheets were obtained as shown in Figure 1. The crystal structure of $\mathrm{Co}_{3} \mathrm{FeN}$ can be detected by X-ray diffraction (XRD). As shown in Figure 1a, the diffraction peaks of the $\mathrm{Co}_{3} \mathrm{FeN}$ could be assigned to $\mathrm{Co}_{3} \mathrm{~N}$ (PDF No.04-021-6263) with a negative shift, indicating the increased lattice spacing over $\operatorname{Co}_{3} \mathrm{~N}$ with the introducing of $\mathrm{Fe}$. In the case of the corresponding $\mathrm{Co}_{3} \mathrm{Fe}$ oxide and $\mathrm{LDH}$, the crystal structures are also consistent with the standard patterns, as shown in Figure S2. Besides the obtained $\mathrm{Co}_{3} \mathrm{FeN}$ maintained the 2D morphology as shown in Figure 1b, there were numerous pores among the interconnected block-like nanocrystallites on the in-plate surface with average hole sizes of about $10-12 \mathrm{~nm}$.
These holes were formed by the phase transformation and Kirkendall effect in the phase transformation process. This phenomenon can also occur in the $\mathrm{Co}_{3} \mathrm{Fe}$ oxide materials as shown in Figure S3. Such an open structure can not only provide numerous active sites for the reaction, but also facilitates the removal of solvent or gas through the holes, resulting in a high-speed-reaction kinetic rate. The element distribution of the $\mathrm{Co}_{3} \mathrm{FeN}$ was investigated by scanning transmission electron microscope assisted by element dispersive spectroscopy (STEM-EDS). As shown in the EDS elemental mapping of Figure $\mathbf{1}(\mathbf{c}-\mathbf{f})$, it is revealed that the $\mathrm{Co}, \mathrm{Fe}$, and $\mathrm{N}$ are homogenously distributed over the whole 2D holey wrinkled nanosheets with 62.54 atom\% of $\mathrm{Co}, 20.58$ atom $\%$ of $\mathrm{Fe}$, and 16.88 atom\% of N. As indicated in Figure S4, the $\mathrm{Co}_{3} \mathrm{FeN}$ nanosheets show a crystal structure with a strong highly-oriented pattern, which can significantly increase the electrical conductivity. ${ }^{40,53}$ It is well known that there is a definite link between electrical conductivity and catalytic activity. High electrical conductivity can dramatically accelerate the kinetic rate of the catalytic reaction. The optimized atomic configuration and density of states were calculated using density functional theory (DFT) and are presented in Figure 1(g, h) and Figure S5 and S6. To obtain lowest energy Fe/Co ordering, 20 structures with lowest electrostatic energy are optimized and calculated by DFT. The energy distribution of all the calculated orderings are demonstrated in Figure S5. The density of states (DOS) of $\mathrm{Co}_{3} \mathrm{FeN}$ near the Fermi level is more intense than that of $\mathrm{Co}_{3} \mathrm{Fe}$ oxide, indicating that the $\mathrm{Co}_{3} \mathrm{FeN}$ turns out to be metallic state while $\mathrm{Co}_{3} \mathrm{Fe}$ oxide turns out to be half metal state. Co states were predicted to be the main contributors to the states near the Fermi level. The variations in the surface area and pore size range before and after the nitridation process were further characterized, as shown in Figure S7. After the nitridation process, the specific surface area was dramatically enlarged from 106.6 to $176.6 \mathrm{~m}^{2} \mathrm{~g}^{-1}$, while numerous nanopores were generated. Atomic force microscopy (AFM) was carried out to evaluate the thickness and surface structure of the $2 \mathrm{D}$ holey wrinkled $\mathrm{Co}_{3} \mathrm{FeN}$ nanosheets, as shown in Figure 1(i, j). The $2 \mathrm{D}$ holey wrinkled $\mathrm{Co}_{3} \mathrm{FeN}$ nanosheets have an ultrathin structure with a thickness of about $4 \mathrm{~nm}$. 


\section{Journal of Materials Chemistry A}

\section{ARTICLE}
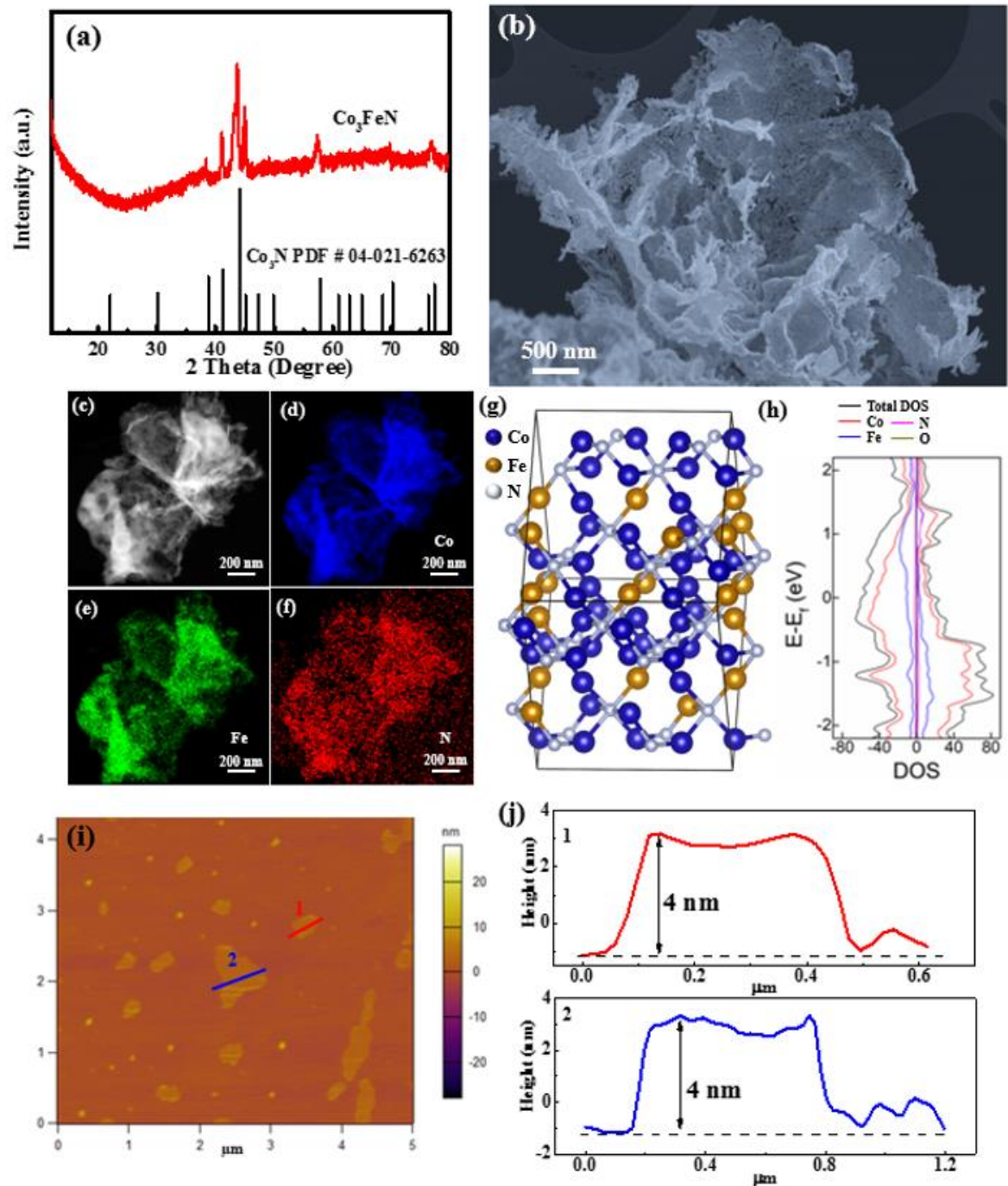

Figure 1. (a) XRD pattern and (b) SEM image of 2D holey wrinkled Co 3 FeN nanosheets; (c-f) STEM-EDS images of 2D holey wrinkled $\mathrm{Co}_{3} \mathrm{FeN}$ nanosheets; calculated $(\mathrm{g})$ structure and $(\mathrm{h})$ density of states for $\mathrm{Co}_{3} \mathrm{FeN}$ nanosheets; (i-j) AFM results for the $2 \mathrm{D}$ holey wrinkled $\mathrm{Co}_{3} \mathrm{FeN}$ nanosheets

X-ray photoelectron spectroscopy (XPS) was also conducted to analyze the chemical states of the materials, as shown in Figure 2. For the $2 \mathrm{D}$ holey wrinkled $\mathrm{Co}_{3} \mathrm{FeN}$ nanosheets, the high resolution XPS spectrum of Co $2 p$ splits into Co $2 p_{3 / 2}$ and Co $2 p_{1 / 2}$ species (Figure 2a). The peaks at 781.1 and $797.5 \mathrm{eV}$ can be assigned to Co-N or Co$\mathrm{O}$ species. And peaks at 777.2 and $795.7 \mathrm{eV}$ could be attributed to metallic Co. The satellite peaks of Co $2 p$ located at 786.2 and 803.7 $\mathrm{eV}$ could be attributed to $\mathrm{Co}-\mathrm{OH}$ bonds, implying the unavoidably presence of partial surface oxidation under atmospheric exposure. ${ }^{33}$
Figure $2 \mathbf{b}$ shows the spectrum of Fe $2 p$, where the peaks at around 706.5 and $720.1 \mathrm{eV}$ are assigned to $\mathrm{Fe}^{3+}-\mathrm{N}$ bonds. The two peaks located at 711.3 and $723.6 \mathrm{eV}$ could be attributed to $\mathrm{Fe}^{2+}$ or $\mathrm{Fe}^{3+}$. The $\mathrm{N} 1 s$ spectrum is split into two peaks: the peak at $397.2 \mathrm{eV}$ is ascribed to $\mathrm{Co}-\mathrm{N}$ bonds, and the peak at $398.7 \mathrm{eV}$ is ascribed to $\mathrm{Co} / \mathrm{Fe}-\mathrm{N}$ bonds (Figure 2c). In addition, the atomic ratio of Co is 61.40 atom\%, $\mathrm{Fe}$ is 21.34 atom\%, and $N$ is 17.26 atom\% based on XPS survey, which is similar with the EDS results. When compared with the $2 \mathrm{D}$ holey wrinkled $\mathrm{Co}_{3} \mathrm{FeN}$ nanosheets, the $\mathrm{Co}$ spectrum of the $2 \mathrm{D}$ holey wrinkle $\mathrm{Co}_{3} \mathrm{Fe}$ oxide presents a positive shift at $2 p_{3 / 2}$ and a negative shift at $2 p_{1 / 2}$, indicating an inflection of the surface electronic band 
bending (Figure 2d). In addition, the peak at lower binding energy is significantly increased for $2 \mathrm{D}$ holey wrinkled $\mathrm{Co}_{3} \mathrm{Fe}$ oxide. For $\mathrm{Fe} 2 \mathrm{p}$ of the $2 \mathrm{D}$ holey wrinkled $\mathrm{Co}_{3} \mathrm{Fe}$ oxide (Figure 2e), the ratio of the two peaks at lower binding energy decreased associated with a negative shift, indicating that less electron was transferred to $\mathrm{Fe}$ atoms. Figure $2 \mathrm{f}$ presents the $\mathrm{O} 1 s$ spectrum of the $2 \mathrm{D}$ holey wrinkled $\mathrm{Co}_{3} \mathrm{Fe}$ oxide. The peaks located at 529.1 and $531.6 \mathrm{eV}$ could be assigned to the $\mathrm{O}^{2-}$
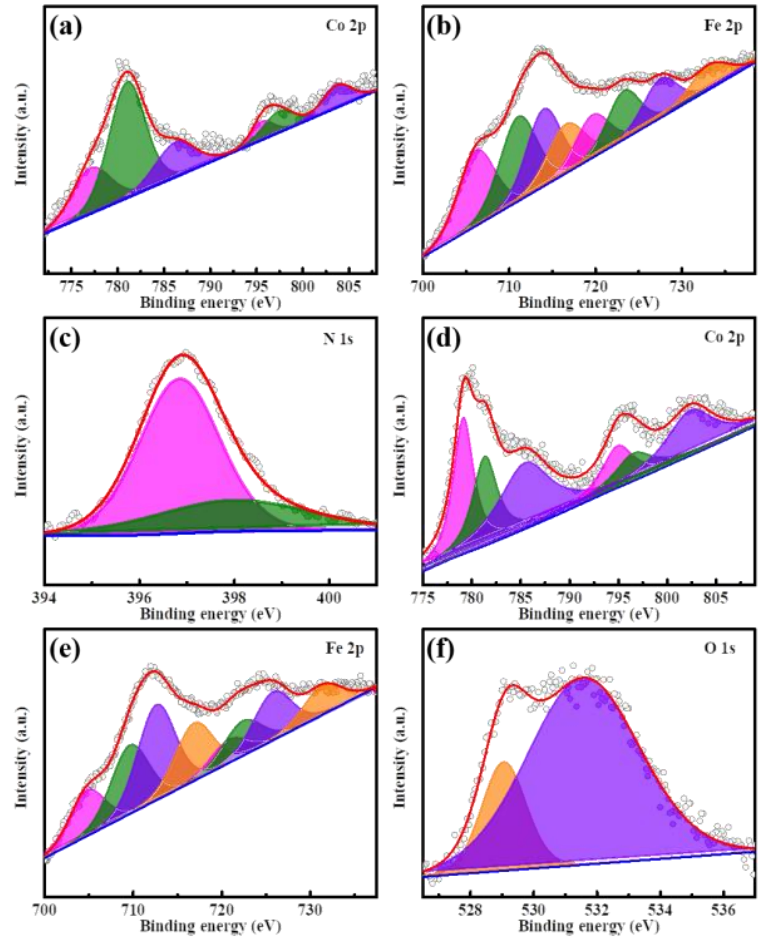

ions in cobalt oxide and surface hydroxyl/adsorbed oxygen species, respectively.

Figure 2. XPS spectra of (a) Co $2 p$, (b) Fe $2 p$, and (c) N $1 s$ for the 2D holey wrinkled $\mathrm{Co}_{3} \mathrm{FeN}$ nanosheets, and (d) $\mathrm{Co} 2 p$, (e) Fe $2 p$, and (f) $\mathrm{O} l s$ for the $2 \mathrm{D}$ holey wrinkled $\mathrm{Co}_{3} \mathrm{Fe}$ oxide nanosheets.

The electrocatalytic performance of the 2D holey-structured wrinkled $\mathrm{Co}_{3} \mathrm{FeN}$ nanosheets towards the OER and the ORR was investigated by linear sweep voltammetry (LSV) in $\mathrm{O}_{2}$-saturated $0.1 \mathrm{M} \mathrm{KOH}$ electrolyte using a rotating disk electrode. The 2D holey wrinkled $\mathrm{Co}_{3} \mathrm{Fe}$ oxide nanosheets and $2 \mathrm{D}$ wrinkled $\mathrm{Co}_{3} \mathrm{Fe} \mathrm{LDH}$ nanosheets were also measured for comparison. The polarization curves of the different samples at a scan rate of $5 \mathrm{mV} \mathrm{s}^{-1}$ and a rotation speed of $1600 \mathrm{rpm}$ are shown in Figure 3a. The 2D holey wrinkled $\mathrm{Co}_{3} \mathrm{FeN}$ nanosheets exhibited the best ORR activity among these three catalysts, with onset potential of $0.89 \mathrm{~V}$ and significantly larger diffusion-limited current density of $4.87 \mathrm{~mA} \mathrm{~cm}{ }^{-2}$, suggesting that oxygen is more easily reduced on the $2 \mathrm{D}$ holey wrinkled $\mathrm{Co} 3 \mathrm{FeN}$ nanosheets. The $2 \mathrm{D}$ holey wrinkled $\mathrm{Co}_{3} \mathrm{Fe}$ oxide nanosheets showed an onset potential of $0.81 \mathrm{~V}$ and a diffusion-limited current density of $3.98 \mathrm{~mA} \mathrm{~cm}^{-2}$, respectively, which is better than for the $2 \mathrm{D}$ wrinkle $\mathrm{Co}_{3} \mathrm{Fe} \mathrm{LDH}$ nanosheets $\left(0.82 \mathrm{~V}\right.$ and $\left.3.47 \mathrm{~mA} \mathrm{~cm}^{-2}\right)$. Moreover, the Tafel slope of the $2 \mathrm{D}$ holey wrinkled $\mathrm{Co}_{3} \mathrm{FeN}$ nanosheets was the smallest among the samples, as shown in Figure $\mathbf{3 b}$, which further confirms the excellent ORR performance of the 2D holey wrinkled $\mathrm{Co}_{3} \mathrm{FeN}$ nanosheets. The number of electrons transferred in the ORR was determined according to the Koutechy-Levich (K-L) equation. The number of electrons transferred for $2 \mathrm{D}$ holey wrinkled $\mathrm{Co} 3 \mathrm{FeN}$ nanosheets was calculated to be $\sim 4$, indicating fast kinetics through the desired four-electron-transfer ORR pathway (Figure S8). In addition, the $2 \mathrm{D}$ holey wrinkled $\mathrm{Co}_{3} \mathrm{FeN}$ nanosheets also exhibit excellent OER activity. As shown in Figure 3c, it is clear that the 2D holey wrinkled $\mathrm{Co}_{3} \mathrm{FeN}$ nanosheets featured a significantly lower overpotential and a higher current density in the provided potential range when compared with the other samples. For example, the $2 \mathrm{D}$ holey wrinkled $\mathrm{Co}_{3} \mathrm{FeN}$ nanosheets showed an overpotential of 420 $\mathrm{mV}$ to deliver a current density of $10 \mathrm{~mA} \mathrm{~cm}^{-2}$, which is better than those of the 2D holey wrinkled $\mathrm{Co}_{3} \mathrm{Fe}$ oxide nanosheets $(520 \mathrm{mV})$ and $2 \mathrm{D}$ wrinkled $\mathrm{Co}_{3} \mathrm{Fe} \mathrm{LDH}$ nanosheets $(578 \mathrm{mV})$. Furthermore, the $2 \mathrm{D}$ holey wrinkled $\mathrm{Co}_{3} \mathrm{FeN}$ nanosheets exhibited a much lower Tafel slope than those of the 2D holey wrinkled $\mathrm{Co}_{3} \mathrm{Fe}$ oxide nanosheets and the $2 \mathrm{D}$ wrinkled $\mathrm{Co}_{3} \mathrm{Fe} \mathrm{LDH}$ nanosheets, indicating the high intrinsic OER kinetics of the 2D holey wrinkled $\mathrm{Co}_{3} \mathrm{FeN}$ nanosheets (Figure 3d). The durability of $2 \mathrm{D}$ holey wrinkled $\mathrm{Co}_{3} \mathrm{FeN}$ nanosheets as a bifunctional electrocatalyst was also investigated for the OER and the ORR using the chronoamperometric method. As shown in Figure S9, the $2 \mathrm{D}$ holey wrinkled $\mathrm{Co}_{3} \mathrm{FeN}$ nanosheets demonstrated an excellent electrocatalytic stability during both the OER and ORR than those of the commerical $\mathrm{RuO}_{2}, \mathrm{Pt} / \mathrm{C}$, and other samples without any obvious decay of activities over a long time continuous operation. The good electrochemical stability of $2 \mathrm{D}$ holey wrinkled $\mathrm{Co}_{3} \mathrm{FeN}$ nanosheets could be attributed to its high chemical stability and outstanding structure durability. As shown in Figure 3e, the 2D holey wrinkled $\mathrm{Co}_{3} \mathrm{FeN}$ nanosheets demonstrated the lowest potential difference between $E_{\mathrm{j}=10}$ of the OER and $E_{1 / 2}$ of the ORR $(0.86 \mathrm{~V})$, which is significantly lower than those of the $2 \mathrm{D}$ holey wrinkled $\mathrm{Co}_{3} \mathrm{Fe}$ oxide $(1.01 \mathrm{~V})$ and the $2 \mathrm{D}$ wrinkled $\mathrm{Co}_{3} \mathrm{Fe} \mathrm{LDH}(1.10 \mathrm{~V})$. The importance of the holey wrinkled nanosheet architecture for the catalytic activity could be reflected by the electrochemically active surface area (ECSA), which represents the electrochemically accessible area of the electrode material to the electrolyte that is utilized for charge transfer and catalytic reactions. ${ }^{54,} 55$ The ECSA was estimated from the electrochemical double-layer capacitace $\left(C_{\mathrm{dl}}\right)$, which is half the value of the linear slope (capacitive current $v s$. scan rate). As can be seen in Figure 3f and Figure S10, the 2D holey wrinkled $\mathrm{Co}_{3} \mathrm{FeN}$ nanosheets exhibited the largest $C_{\mathrm{dl}}$ compared with those of $2 \mathrm{D}$ holey wrinkled $\mathrm{Co}_{3} \mathrm{Fe}$ oxide nanosheets and $2 \mathrm{D}$ wrinkled $\mathrm{Co}_{3} \mathrm{Fe} \mathrm{LDH}$ nanosheets due to an optimized combination of large active sites and metallic state. 

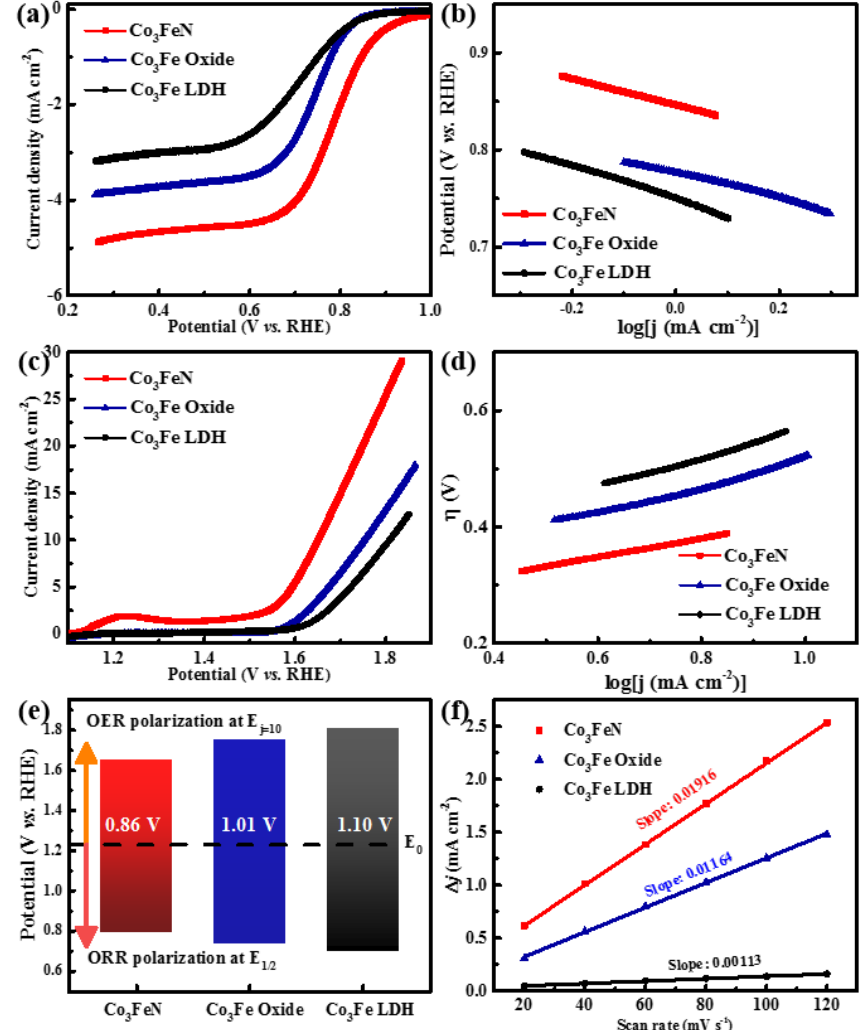

Figure 3. (a) LSV curves and (b) Tafel plots of different samples for the ORR in $0.1 \mathrm{M} \mathrm{KOH}$ at $1600 \mathrm{rpm}$, (c) LSV curves and (d) Tafel plots of different samples for the OER in $0.1 \mathrm{M} \mathrm{KOH}$ at $1600 \mathrm{rpm}$, (e) potential differences between the $E_{j=10}$ for the OER and $E_{1 / 2}$ for the ORR for all samples, (f) differences in the current density $\left(\Delta j=j_{\text {anode }}\right.$ - $j_{\text {cathode }}$ ) for the samples plotted $v s$. the scan rate.

2D holey winkled $\mathrm{Co}_{3} \mathrm{FeN}$ nanosheets were employed as an efficient bifunctional air electrode electrocatalyst in a zinc-air battery. The zinc-air battery was fabricated using catalyst-loaded carbon paper as the air cathode, zinc foil as the anode, and 0.2 $\mathrm{M} \mathrm{ZnAc}_{2}$ and $6.0 \mathrm{M}$ $\mathrm{KOH}$ as the electrolyte. As shown in Figure S11, the zinc-air battery with $2 \mathrm{D}$ holey wrinkled $\mathrm{Co}_{3} \mathrm{FeN}$ nanosheets as air electrode catalyst revealed an open-circuit potential of $1.583 \mathrm{~V}$, which is higher than these of 2D holey wrinkle $\mathrm{Co}_{3} \mathrm{Fe}$ oxide nanosheets $(1.330 \mathrm{~V})$ and $2 \mathrm{D}$ wrinkle $\mathrm{Co}_{3} \mathrm{Fe} \mathrm{LDH}$ nanosheets $(1.308 \mathrm{~V})$. The charge and discharge polarization curves of the rechargeable zinc-air battery fabricated from different samples were recorded and are compared in Figure 4a. It is obvious that the $2 \mathrm{D}$ holey wrinkled $\mathrm{Co} 3 \mathrm{FeN}$ nanosheets exhibited the best performance with the lowest overpotential during all of the current density tests when compared with the 2D holey wrinkled $\mathrm{Co}_{3} \mathrm{Fe}$ oxide nanosheets and $2 \mathrm{D}$ wrinkled $\mathrm{Co} 3 \mathrm{Fe} \mathrm{LDH}$ nanosheets. Figure 4b shows that the maximum power density of the zinc-air battery using the $2 \mathrm{D}$ holey winkled $\mathrm{Co}_{3} \mathrm{FeN}$ nanosheets was determined to be $108 \mathrm{~mW} \mathrm{~cm}^{-2}$, which is higher than those of the 2D holey $\mathrm{Co}_{3} \mathrm{Fe}$ oxide nanosheets $\left(65 \mathrm{~mW} \mathrm{~cm}^{-2}\right)$ and the $2 \mathrm{D} \mathrm{Co} \mathrm{Co}_{3} \mathrm{FeH}$ nanosheets $\left(42 \mathrm{~mW} \mathrm{~cm} \mathrm{~cm}^{-2}\right)$. The zinc-air battery with the $2 \mathrm{D}$ holey wrinkled $\mathrm{Co}_{3} \mathrm{FeN}$ nanosheet electrocatalyst exhibited the best performance, and it significantly outperformed zinc-air batteries with the $2 \mathrm{D}$ holey wrinkled $\mathrm{Co}_{3} \mathrm{Fe}$ oxide nanosheets and the $2 \mathrm{D}$ wrinkled $\mathrm{Co}_{3} \mathrm{Fe} \mathrm{LDH}$ nanosheet catalysts during the discharge process. As shown in Figure 4c, the internal resistance of the zinc-air battery with a $2 \mathrm{D}$ holey wrinkled $\mathrm{Co}_{3} \mathrm{FeN}$ nanosheet air cathode is smaller than those with $2 \mathrm{D}$ holey wrinkled $\mathrm{Co}_{3} \mathrm{Fe}$ oxide nanosheets and $2 \mathrm{D}$ wrinkled $\mathrm{Co}_{3} \mathrm{Fe}$ LDH nanosheet electrodes. In addition, the 2D holey wrinkled $\mathrm{Co}_{3} \mathrm{FeN}$ nanosheets only exhibited an overpotential of 0.90 $\mathrm{V}$, which is significantly lower than those of the 2D holey wrinkled $\mathrm{Co}_{3} \mathrm{Fe}$ oxide nanosheets $(0.96 \mathrm{~V})$ and the $2 \mathrm{D}$ wrinkled $\mathrm{Co}_{3} \mathrm{Fe} \mathrm{LDH}$ nanosheets $(1.17 \mathrm{~V})$ (Figure $4 \mathbf{d}-\mathbf{f}$ ). The specific capacities of zincair battery with different samples were measured based on consumed $\mathrm{Zn}$ anode. As shown in Figure S12. the $2 \mathrm{D}$ holey wrinkled $\mathrm{Co}_{3} \mathrm{FeN}$ nanosheets demonstrated the largest specific capacity of $890 \mathrm{~mA} \mathrm{~h} \mathrm{~g}^{-}$ ${ }^{1}$ compared to that of $\mathrm{Co}_{3} \mathrm{Fe}$ oxide $\left(836 \mathrm{~mA} \mathrm{~h} \mathrm{~g}^{-1}\right)$ and $\mathrm{Co}_{3} \mathrm{Fe} \mathrm{LDH}$ $\left(798 \mathrm{~mA} \mathrm{~h} \mathrm{~g}^{-1}\right)$. Furthermore, the cycling stability of the batteries was also tested at a current density of $5 \mathrm{~mA} \mathrm{~cm}^{-2}$ (Figure $4 \mathrm{~g}$ ). The overpotential of 2D wrinkle $\mathrm{Co}_{3} \mathrm{Fe} \mathrm{LDH}$ nanosheets catalysts increased dramatically to $1.44 \mathrm{~V}$ only after 47 hours. And the overpotential of 2D holey winkle $\mathrm{Co}_{3} \mathrm{Fe}$ oxide nanosheets also increased to $1.15 \mathrm{~V}$ after 100 hours. The $2 \mathrm{D}$ holey wrinkled $\mathrm{Co}_{3} \mathrm{FeN}$ nanosheets exhibited excellent cycling stability with no obvious voltage fading for both the discharge and the charge process, even after 150 hours. The round-trip voltage (difference between charging/discharging potential) of the $2 \mathrm{D}$ holey wrinkled $\mathrm{Co}_{3} \mathrm{FeN}$ nanosheets was $0.90 \mathrm{~V}$ at the $1^{\text {st }}$ cycle, which slightly decreased to $0.83 \mathrm{~V}$ at about 83 hours $\left(500^{\text {th }}\right.$ cycle) and remains at $0.84 \mathrm{~V}$ even after 150 hours (900 cycles) as shown in Figure 4g. And the comparison of the electrocatalytic performance with those of currently reported state-of-the-art electrocatalysts as listed in Table S1, indicating the excellent electrocatalytic activity of 2D holey wrinkled $\mathrm{Co}_{3} \mathrm{FeN}$ nanosheets as stable and bifunctional electrocatalyst for zincair batteries. All of the above results verify the excellent activity and stability of the 2D holey wrinkled $\mathrm{Co}_{3} \mathrm{FeN}$ nanosheet catalyst in ORR/OER catalysis and zinc-air batteries. HRTEM was also employed to investigate the structure change of $2 \mathrm{D}$ holey wrinkled $\mathrm{Co}_{3} \mathrm{FeN}$ nanosheets after long-time cycling. As revealed in Figure S13 and Figure 4(h-i), the 2D holey wrinkled $\mathrm{Co}_{3} \mathrm{FeN}$ nanosheet structure was still well preserved after cycling. The high resolution TEM image reveals that the surface of $\mathrm{Co}_{3} \mathrm{FeN}$ remains unchanged, suggesting that the $\mathrm{Co}_{3} \mathrm{FeN}$ could effectively prevent the aggregation of active materials and resist the highly concentrated basic solution. And as shown in Figure S14, the diffraction peaks of $\mathrm{Co}_{3} \mathrm{FeN}$ and $\mathrm{Co}_{3} \mathrm{Fe}$ oxide still could be well detected without any other impurity, indicating that the major phase of $\mathrm{Co}_{3} \mathrm{FeN}$ and $\mathrm{Co}_{3} \mathrm{Fe}$ oxide remain unchanged. That stable structure could preserve the exposed active large lateral edge and guarantee the excellent stability shown during the prolonged cycling test. The $2 \mathrm{D}$ holey wrinkle $\mathrm{Co}_{3} \mathrm{Fe}$ oxide nanosheets and $2 \mathrm{D}$ wrinkle $\mathrm{Co} 3 \mathrm{Fe} \mathrm{LDH}$, however, could not maintain their structure and pulverized to nanoparticles associate with significant decrease of edge plane, leading to the decay of catalytic activity. 


\section{ARTICLE}
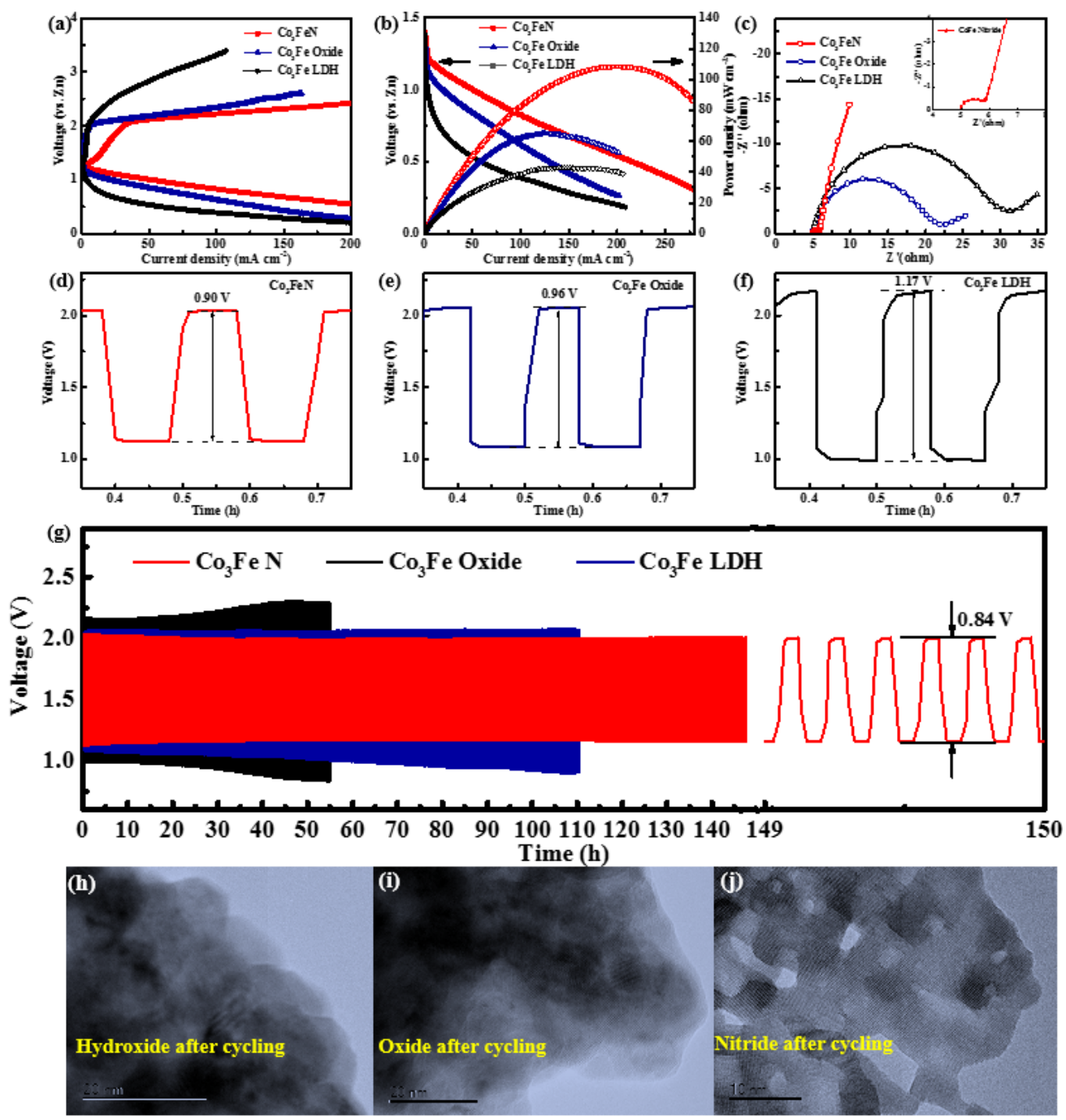

Figure 4. (a) Galvanodynamic discharge and charge polarization curves of the different samples, (b) discharge polarization curves and corresponding power density curves of the different samples, (c) Nyquist plots of different samples, with the inset showing an enlargement for $\mathrm{Co}_{3} \mathrm{FeN}$, (d) the discharge/charge curves of 2D holey wrinkled $\mathrm{Co}_{3} \mathrm{FeN}$ nanosheets, (e) the discharge/charge curves of $2 \mathrm{D}$ holey wrinkled $\mathrm{Co}_{3} \mathrm{Fe}$ oxide nanosheets, (f) the discharge/charge curves of 2D wrinkled $\mathrm{Co}_{3} \mathrm{Fe} \mathrm{LDH}$ nanosheets, (g) galvanostatic discharge and charge cycling stability of 2D holey wrinkled $\mathrm{Co}_{3} \mathrm{FeN}$ nanosheets, $2 \mathrm{D}$ holey wrinkled $\mathrm{Co}_{3} \mathrm{Fe}$ oxide nanosheets, and $2 \mathrm{D}$ wrinkled $\mathrm{Co} 3 \mathrm{Fe} \mathrm{LDH}$ nanosheets, (hj) the morphology of the corresponding materials after long-time cycling. 


\section{Journal of Materials Chemistry A}

\section{ARTICLE}

The surface adsorption energy of the 2D holey wrinkled $\mathrm{Co}_{3} \mathrm{FeN}$ nanosheets were investigated using density functional theory (DFT) calculations, as shown in Figure 5. The different types of (111) and (110) surfaces of $\mathrm{Co}_{3} \mathrm{FeN}$ and $\mathrm{Co}_{3} \mathrm{Fe}$ oxide were modeled, respectively. The adsorption energy of an $\mathrm{OH}^{*}$ group on each surface was examined, and the results are presented in Table 1. Due to the potential arrangement of terminated atoms, there could be two types of (110) surface and one type of (111) surface for $\mathrm{Co}_{3} \mathrm{FeN}$ and one type for both (110) surfaces and (111) surfaces for $\mathrm{Co}_{3} \mathrm{Fe}$ oxide. As indicated by the adsorption energy, as shown in Table 1, for $\mathrm{Co}_{3} \mathrm{FeN}$, the most active surface for $\mathrm{OH}^{*}$ would be the (110) surface with Type II surface orientation, because the Co site on the type II (110) surface has the lowest adsorption energy. Therefore, the Co site would act as the active site for the reaction because $\mathrm{OH}^{*}$ tend to be adsorbed to the Co site. When comes to $\mathrm{Co}_{3} \mathrm{Fe}$ oxide, the most active surface would be the (110) surface, given that the Co site shows the lowest adsorption energy.

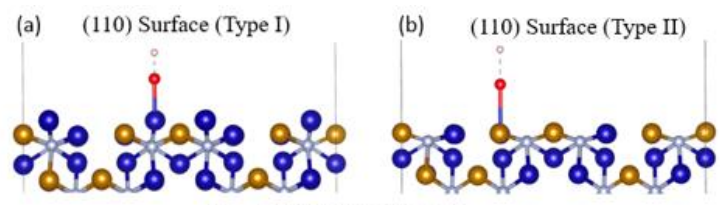

(c) (111) Surface (Type I)

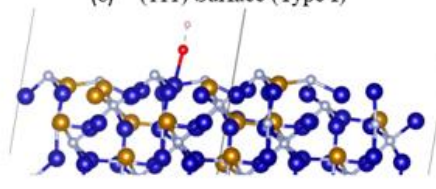

(d) (110) Surface (Type I)

(e) (111) Surface (Type I)

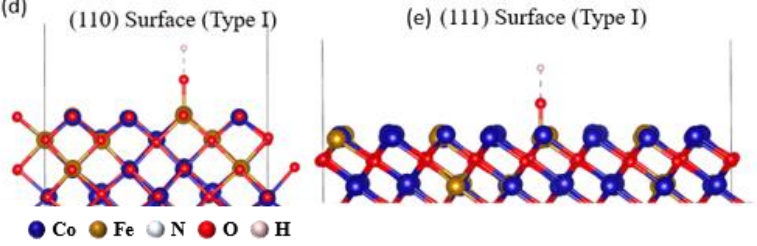

Figure 5 Atomic structure and $\mathrm{OH}^{*}$ absorption energy of (a-c) $\mathrm{Co}_{3} \mathrm{FeN}$; (b-e) $\mathrm{Co}_{3} \mathrm{Fe}$ oxide on different crystalline surfaces.
Table 1: Calculated adsorption energy of $\mathrm{OH}^{*}$ on different surface configurations.

\begin{tabular}{|c|c|c|c|c|c|c|}
\hline Surface & \multicolumn{4}{|c|}{$\mathrm{Co}_{3} \mathrm{FeN}(110)$} & \multirow{2}{*}{\multicolumn{2}{|c|}{$\begin{array}{c}\mathrm{Co}_{3} \mathrm{FeN}(111) \\
\text { Type I }\end{array}$}} \\
\hline Type & \multicolumn{2}{|c|}{ Type I } & \multicolumn{2}{|c|}{ Type II } & & \\
\hline Ads. Site & $\begin{array}{c}\text { Co } \\
\text { Site }\end{array}$ & $\begin{array}{c}\mathrm{Fe} \\
\text { Site }\end{array}$ & $\begin{array}{l}\text { Co } \\
\text { Site }\end{array}$ & $\begin{array}{c}\mathrm{Fe} \\
\text { Site }\end{array}$ & $\begin{array}{c}\mathrm{Fe} \\
\text { Site }\end{array}$ & Co Site \\
\hline $\begin{array}{c}\text { EAdsorp } \\
(\mathrm{eV})\end{array}$ & -3.73 & -3.30 & -4.30 & -3.67 & 2.02 & 0.18 \\
\hline Surface & \multicolumn{3}{|c|}{$\mathrm{Co}_{3} \mathrm{Fe}$ Oxide (110) } & \multicolumn{3}{|c|}{$\mathrm{Co}_{3} \mathrm{Fe}$ Oxide (111) } \\
\hline Type & \multicolumn{3}{|c|}{ Type I } & \multicolumn{3}{|c|}{ Type I } \\
\hline Ads. Site & $\operatorname{Cos}$ & & Fe Site & $\mathrm{Co}$ & & Fe Site \\
\hline $\begin{array}{c}\text { EAdsorp } \\
(\mathrm{eV})\end{array}$ & -1. & & 1.57 & 2. & & 2.80 \\
\hline
\end{tabular}

\section{Conclusion}

A 2D highly-orientated crystalline structure of bimetallic $\mathrm{Co}_{3} \mathrm{FeN}$ nanosheets was successfully designed and synthesized. Based on the lowest $\mathrm{OH}^{*}$ adsorption energy of the completely exposed large lateral surface, the catalytic properties were improved by numerous active sites along the long lateral edge, enhanced electrical conductivity due to high-orientation crystalline texture and synergistic effects, and greater mechanical stability. The connected porous architecture could also guarantee durability by protecting the electrocatalyst from aggregation and peeling off during long-term cycling. It showed excellent bifunctional activity towards the ORR and the OER, exhibiting a low overpotential of $0.43 \mathrm{~V}$ for the OER reaction and the onset potential of $0.90 \mathrm{~V}$ for the ORR reaction in $0.1 \mathrm{M} \mathrm{KOH}$ solution. In addition, it possesses a maximum power density of $108 \mathrm{~mW} \mathrm{~cm}{ }^{-2}$ and cycle life of 900 cycles with a low round-trip voltage of $0.84 \mathrm{~V}$. Compared with $\mathrm{LDH}$ and oxide materials, the $\mathrm{Co}_{3} \mathrm{FeN}$ nanosheets are quite stable in an oxygen-rich electrochemical environment, keeping high-orientation crystalline texture during the whole cycling period. This work will open up a new avenue for the design of advanced 2D holey wrinkled bifunctional catalysts for next-generation energy storage and conversion technologies such as metal-air batteries and fuel cells. 


\section{Experimental Section}

\section{Experimental Methods}

Synthesis of $\mathrm{Co}_{3} \mathrm{Fe}-\mathrm{LDH}$ : In general, polyethylene oxide polypropylene oxide - polyethylene oxide (P123, $200 \mathrm{mg}$ ) was dispersed into ethanol $(13 \mathrm{~mL})$ under vigorous stirring for $10 \mathrm{~min}$, followed by adding $0.5 \mathrm{~mL} \mathrm{Co}\left(\mathrm{CH}_{3} \mathrm{COO}\right)_{2} \cdot 4 \mathrm{H}_{2} \mathrm{O}$ solution $(1 \mathrm{~mol} \cdot \mathrm{L}$ $\left.{ }^{1}\right), 0.2 \mathrm{~mL} \mathrm{Fe}\left(\mathrm{CH}_{3} \mathrm{COO}\right)_{2}$ solution $\left(1 \mathrm{~mol} \cdot \mathrm{L}^{-1}\right)$ and $0.3 \mathrm{~mL}$ hexamethylenetetramine solution $\left(0.17 \mathrm{~mol} \cdot \mathrm{L}^{-1}\right)$. After stirring for 30 min, ethylene glycol $(13 \mathrm{~mL})$ was added into the solution. After another $10 \mathrm{~min}$, the reaction proceeded for $3 \mathrm{~h}$ in a Teflon-lined autoclave at $170{ }^{\circ} \mathrm{C}$ after aging for $24 \mathrm{~h}$. The $\mathrm{Co}_{3} \mathrm{Fe}$ layered double hydroxide $(\mathrm{LDH})$ was obtained after washing the product several times.

Synthesis of $2 \mathrm{D}$ holey wrinkled $\mathrm{Co}_{3} \mathrm{Fe}$ oxide nanosheets: To synthesize 2D holey wrinkled $\mathrm{Co}_{3} \mathrm{Fe}$ oxide nanosheets, $\mathrm{Co}_{3} \mathrm{Fe} \mathrm{LDH}$ nanosheets were calcined for $1 \mathrm{~min}$ in $\mathrm{O}_{2}$ atmosphere at $500{ }^{\circ} \mathrm{C}$ (ramp rate $\sim 10$ $\left.{ }^{\circ} \mathrm{C} \min ^{-1}\right)$.

Synthesis of $2 \mathrm{D}$ holey wrinkled $\mathrm{Co}_{3} \mathrm{FeN}$ nanosheets: To synthesize 2D holey wrinkled $\mathrm{Co}_{3} \mathrm{FeN}$ nanosheets, $\mathrm{Co}_{3} \mathrm{Fe} \mathrm{LDH}$ nanosheets were calcined $1 \mathrm{~min}$ in $\mathrm{NH}_{3}$ atmosphere at $500{ }^{\circ} \mathrm{C}$ (ramp rate $\sim 10{ }^{\circ} \mathrm{C} \mathrm{min}$ 1).

Materials characterization: The crystalline structures were analysed by GBC MMA powder X-ray diffraction. For the morphology, a JEOL JSM-7500FA scanning electron microscopy (SEM) and a JEMARM200F transmission electron microscopy (TEM) were utilized. Atomic force microscopy (AFM) was also conducted (Asylum AFM facility).

Electrochemical measurements: A three-electrode glass cell with an $\mathrm{Ag} / \mathrm{AgCl}$ reference electrode and a graphite rod counter electrode was employed on Princeton 2273 and 616 workstations to test electrochemical performance. In order to make the catalyst inks, $5 \mathrm{mg}$ of sample was added into a mixed solution $(1100 \mu \mathrm{L})$ composed of 5 $\%$ Nafion ${ }^{\circledR}$ solution $(100 \mu \mathrm{L})$, isopropanol $(250 \mu \mathrm{L})$, and deionised (DI) water $(750 \mu \mathrm{L})$. The working electrodes were obtained through dripping the catalyst ink $(5 \mu \mathrm{L})$ on pre-polished glassy carbon disk electrodes and drying for $20 \mathrm{~min}$ in an $80{ }^{\circ} \mathrm{C}$ oven. Linear sweep voltammetry was performed in $0.1 \mathrm{M} \mathrm{KOH}$. To determine the active surface areas, electrochemical double-layer capacitance measurements were performed between 0.2 and $0.3 \mathrm{~V}$ at various scan rates. All potentials were referenced to reversible hydrogen electrode (RHE) using the following calculation: $E_{\mathrm{RHE}}=0.059 \mathrm{pH}+0.197+$ $E_{\mathrm{Ag} / \mathrm{AgCl}}$.

Zinc-Air Battery Tests: The measurements on rechargeable zinc-air batteries were performed using home-built electrochemical cells. All data were collected from the as-fabricated cell with a battery tester at room temperature. Generally, zinc foil was used as the anode and catalysts loaded on carbon cloth with a diameter of about $1 \mathrm{~cm}$ (catalyst loading amount of $1.0 \mathrm{mg} \mathrm{cm}^{-2}$ ) was used as the air cathode. For comparison, a rechargeable battery was also made from $2 \mathrm{D}$ holey wrinkled $\mathrm{Co}_{3} \mathrm{Fe}$ oxide nanosheets and $2 \mathrm{D} \mathrm{Co}_{3} \mathrm{Fe} \mathrm{LDH}$ nanosheets. The electrolyte was mixed solution of $6 \mathrm{~mol} \cdot \mathrm{L}^{-1} \mathrm{KOH}$ and $0.2 \mathrm{~mol} \cdot \mathrm{L}^{-}$ ${ }^{1}$ zinc acetate.

Computational methodologies: First-principles density functional theory (DFT) calculations were performed for atomic configuration optimization and energetic calculations. For both $\mathrm{Co}_{3} \mathrm{FeN}$ and $\mathrm{Co}_{3} \mathrm{Fe}$ oxide, a $2 \times 2 \times 2$ supercell was constructed while different types of $\mathrm{Co} / \mathrm{Fe}$ ordering were enumerated to find the lowest energy configuration. Furthermore, a slab model was constructed for modelling the adsorption at the interface. In all the slab models, the vacuum space was set to be more than $15 \AA$. When calculated the adsorption energy, the following equation was used: $\mathrm{E}_{\text {adsorption }}=\mathrm{E}_{\text {(substrate+molecule) }}-\mathrm{E}_{\text {(substrate) }}-\mathrm{E}_{\text {(molecule) }}$. For all calculations, the Perdew-Burke-Ernzerhof (PBE) functional and projector augmentedwave $(\mathrm{PAW})^{53,56,57}$ method was adopted using the Vienna ab initio simulation package (VASP). The dispersive van der Waals interactions between the surface and molecules were included, using the DFT-D2 method of Grimme ${ }^{58,59}$. In each calculation, an energy cut-off of $520 \mathrm{eV}$ was adopted and an energy difference of less than $0.01 \mathrm{eV}$. When performing the structure optimizations, the system was regarded as converged when the force per atom was less than 0.01 $\mathrm{eV} / \AA$ 


\section{Journal of Materials Chemistry A}

\section{ARTICLE}

\section{Conflicts of interest}

There are no conflicts to declare

\section{Acknowledgements}

This manuscript was written through contributions of all the authors. All the authors have given approval to the final version of the manuscript. All organizations have the equivalent contributions. This work was financially supported by the Australian Research Council (ARC) through a Discovery Project (DP180101453), ARC-LIEF Grants (LE120100104 and LE0237478), Natural Science Foundation of China (21603103), and Natural Science Foundation Committee of Jiangsu Province (BK20171462). The authors would like to thank Dr. Tania Silver for critical reading of the manuscript, and also acknowledge the use of the facilities in the UOW Electron Microscopy Center, with particular thanks to Dr. Gilberto Casillas-Garcia.

\section{Notes and references}

${ }^{a}$ Institute for Superconducting and Electronic Materials, University of Wollongong, Squires Way, Fairy Meadow, NSW 2500, Australia ${ }^{b}$ School of Metallurgy, Northeastern University, Shenyang, 211800 , China

${ }^{\mathrm{c} C o l l e g e}$ of Energy Science and Engineering, Nanjing Tech University, Nanjing, 211800, China

$\dagger$ Footnotes should appear here. These might include comments relevant to but not central to the matter under discussion, limited experimental and spectral data, and crystallographic data.

Electronic Supplementary Information (ESI) available: [details of any supplementary information available should be included here]. See DOI: $10.1039 / \mathrm{b} 000000 \mathrm{x} /$

1. A. S. Arico, P. Bruce, B. Scrosati, J. M. Tarascon and W. van Schalkwijk, Nat. Mater., 2005, 4, 366-377.

2. C. Liu, F. Li, L. P. Ma and H. M. Cheng, Adv. Mater., 2010, 22, E28-62.

3. M. Armand and J. M. Tarascon, Nature, 2008, 451, 652.

4. X. F. Lu, L. Yu and X. W. Lou, Sci. Adv., 2019, 5, eaav6009.

5. J. Fu, F. M. Hassan, J. Li, D. U. Lee, A. R. Ghannoum, G. Lui, M. A. Hoque and Z. Chen, Adv. Mater., 2016, 28, 6421-6428.

6. Z. H. Wang, H. H. Jin, T. Meng, K. Liao, W. Q. Meng, J. L. Yang, D. P. He, Y. L. Xiong and S. C. Mu, Adv. Funct. Mater., 2018, 28, 1802596.
7. Y. J. Li, L. Cui, P. F. Da, K. W. Qiu, W. J. Qin, W. B. Hu, X. W. $\mathrm{Du}, \mathrm{K}$. Davey, T. Ling and S. Z. Qiao, Adv. Mater., 2018, 30, e1804653.

8. X.-W. Gao, J. Yang, K. Song, W.-B. Luo, S.-X. Dou and Y.-M. Kang, J. Mater. Chem. A, 2018, 6, 23445-23456.

9. Z. Wang, H. Jin, T. Meng, K. Liao, W. Meng, J. Yang, D. He, Y. Xiong and S. Mu, Adv. Funct. Mater., 2018, 28, 1802596.

10. M. Zeng, Y. Liu, F. Zhao, K. Nie, N. Han, X. Wang, W. Huang, X. Song, J. Zhong and Y. Li, Adv. Funct. Mater., 2016, 26, 4397-4404.

11. X. F. Lu, Y. Chen, S. Wang, S. Gao and X. W. Lou, Adv. Mater., 2019, 31, 1902339.

12. Y. Li, Q. Zhang, C. Li, H.-N. Fan, W.-B. Luo, H.-K. Liu and S.X. Dou, J. Mater. Chem. A, 2019, DOI: 10.1039/C9TA07845B.

13. B. Q. Li, S. Y. Zhang, B. Wang, Z. J. Xia, C. Tang and Q. Zhang, Energy Environ. Sci., 2018, 11, 1723-1729.

14. F. Meng, H. Zhong, D. Bao, J. Yan and X. Zhang, J. Am. Chem. Soc., 2016, 138, 10226-10231.

15. G. Liu, J. Li, J. Fu, G. Jiang, G. Lui, D. Luo, Y. P. Deng, J. Zhang, Z. P. Cano, A. Yu, D. Su, Z. Bai, L. Yang and Z. Chen, Adv. Mater., 2019, 31, e1806761.

16. X. Guo, T. Zheng, G. Ji, N. Hu, C. Xu and Y. Zhang, J. Mater. Chem. A, 2018, 6, 10243-10252.

17. X. Guo, X. Hu, D. Wu, C. Jing, W. Liu, Z. Ren, Q. Zhao, X. Jiang, C. Xu, Y. Zhang and N. Hu, ACS Appl. Mater. Interfaces, 2019, 11, 21506-21514.

18. Y. Y. Shao, F. Ding, J. Xiao, J. Zhang, W. Xu, S. Park, J. G. Zhang, Y. Wang and J. Liu, Adv. Funct. Mater., 2013, 23, $987-$ 1004.

19. W. Liu, J. Zhang, Z. Bai, G. Jiang, M. Li, K. Feng, L. Yang, Y. Ding, T. Yu, Z. Chen and A. Yu, Adv. Funct. Mater., 2018, 28, 1706675.

20. F. T. Kong, X. H. Fan, A. G. Kong, Z. Q. Zhou, X. Y. Zhang and Y. K. Shan, Adv. Funct. Mater., 2018, 28, 1803973.

21. I. S. Amiinu, X. Liu, Z. Pu, W. Li, Q. Li, J. Zhang, H. Tang, H. Zhang and S. Mu, Adv. Funct. Mater., 2018, 28, 1704638.

22. Q. Wang, L. Shang, R. Shi, X. Zhang, Y. Zhao, G. I. N. Waterhouse, L.-Z. Wu, C.-H. Tung and T. Zhang, Adv. Energy Mater., 2017, 7, 1700467.

23. J. Han, X. Meng, L. Lu, J. Bian, Z. Li and C. Sun, Adv. Funct. Mater., 2019, 0, 1808872.

24. S. S. Shinde, C. H. Lee, J.-Y. Yu, D.-H. Kim, S. U. Lee and J.H. Lee, ACS Nano, 2018, 12, 596-608.

25. S. S. Shinde, C.-H. Lee, A. Sami, D.-H. Kim, S.-U. Lee and J.H. Lee, ACS Nano, 2017, 11, 347-357.

26. H.-F. Wang, C. Tang and Q. Zhang, Adv. Funct. Mater., 2018, 28, 1803329

27. X. Liu, M. Park, M. G. Kim, S. Gupta, G. Wu and J. Cho, Angew. Chem., Int. Ed., 2015, 54, 9654-9658.

28. M. Yu, Z. Wang, C. Hou, Z. Wang, C. Liang, C. Zhao, Y. Tong, X. Lu and S. Yang, Adv. Mater., 2017, 29, 1602868.

29. S. S. Shinde, C. H. Lee, J.-Y. Jung, N. K. Wagh, S.-H. Kim, D.H. Kim, C. Lin, S. U. Lee and J.-H. Lee, Energy Environ. Sci., 2019, 12, 727-738. 
30. P. Chen, K. Xu, Z. Fang, Y. Tong, J. Wu, X. Lu, X. Peng, H. Ding, C. Wu and Y. Xie, Angew. Chem., Int. Ed., 2015, 54, 14710-14714.

31. J. Yin, Y. Li, F. Lv, Q. Fan, Y. Q. Zhao, Q. Zhang, W. Wang, F. Cheng, P. Xi and S. Guo, ACS Nano, 2017, 11, 2275-2283.

32. C. H. Lee, B. Jun and S. U. Lee, ACS Sustainable Chem. Eng., 2018, 6, 4973-4980.

33. Y. Wang, D. Liu, Z. Liu, C. Xie, J. Huo and S. Wang, Chem. Commun., 2016, 52, 12614-12617.

34. L. Han, K. Feng and Z. W. Chen, Energy Technol., 2017, 5, 1908-1911.

35. Y. Sun, T. Zhang, X. Li, D. Liu, G. Liu, X. Zhang, X. Lyu, W. Cai and Y. Li, Chem. Commun., 2017, 53, 13237-13240.

36. Y. Zhang, B. Ouyang, J. Xu, G. Jia, S. Chen, R. S. Rawat and H. J. Fan, Angew. Chem., Int. Ed., 2016, 55, 8670-8674.

37. H. Wu and W. Chen, J. Am. Chem. Soc., 2011, 133, 1523615239.

38. D. R. Deng, F. Xue, Y. J. Jia, J. C. Ye, C. D. Bai, M. S. Zheng and Q. F. Dong, ACS Nano, 2017, 11, 6031-6039.

39. P. Z. Chen, K. Xu, Y. Tong, X. L. Li, S. Tao, Z. W. Fang, W. S. Chu, X. J. Wu and C. Z. Wu, Inorg. Chem. Front., 2016, 3, 236242.

40. H. P. Guo, B. Y. Ruan, W. B. Luo, J. Q. Deng, J. Z. Wang, H. K. Liu and S. X. Dou, ACS Catal., 2018, 8, 9686-9696.

41. G. Fu, Z. Cui, Y. Chen, L. Xu, Y. Tang and J. B. Goodenough, Nano Energy, 2017, 39, 77-85.

42. L. Liu, F. Yan, K. Li, C. Zhu, Y. Xie, X. Zhang and Y. Chen, J. Mater. Chem. A, 2019, 7, 1083-1091.

43. Z. Fang, L. Peng, Y. Qian, X. Zhang, Y. Xie, J. J. Cha and G. Yu, J. Am. Chem. Soc., 2018, 140, 5241-5247.

44. S. Wang, M. Zheng, M. Li, X. Wu and C. Xia, J. Mater. Chem. A, 2016, 4, 5745-5754.

45. Z. Fang, L. Peng, H. Lv, Y. Zhu, C. Yan, S. Wang, P. Kalyani, X. Wu and G. Yu, ACS Nano, 2017, 11, 9550-9557.

46. J. C. Meier, I. Katsounaros, C. Galeano, H. J. Bongard, A. A. Topalov, A. Kostka, A. Karschin, F. Schuth and K. J. J. Mayrhofer, Energy Environ. Sci., 2012, 5, 9319-9330.

47. R. Kou, Y. Shao, D. Mei, Z. Nie, D. Wang, C. Wang, V. V. Viswanathan, S. Park, I. A. Aksay, Y. Lin, Y. Wang and J. Liu, J. Am. Chem. Soc., 2011, 133, 2541-2547.

48. J. Yu, Y. Guo, S. She, S. Miao, M. Ni, W. Zhou, M. Liu and Z. Shao, Adv. Mater., 2018, 30, e1800047.

49. L. Peng, P. Xiong, L. Ma, Y. Yuan, Y. Zhu, D. Chen, X. Luo, J. Lu, K. Amine and G. Yu, Nat. Commun., 2017, 8, 15139.

50. A. Shen, Y. Zou, Q. Wang, R. A. Dryfe, X. Huang, S. Dou, L. Dai and S. Wang, Angew. Chem., Int. Ed., 2014, 53, 1080410808.

51. C. Guan, A. Sumboja, H. Wu, W. Ren, X. Liu, H. Zhang, Z. Liu, C. Cheng, S. J. Pennycook and J. Wang, Adv. Mater., 2017, 29.

52. F. Zhang, S. Xi, G. Lin, X. Hu, X. W. Lou and K. Xie, Adv. Mater., 2019, 31, 1806552.

53. P. Hohenberg and W. Kohn, Phys. Rev., 1964, 136, B864-B871.

54. R. F. Savinell, R. L. Zeller and J. A. Adams, J. Electrochem. Soc., 1990, 137, 489-494.

55. M. Dupont, A. F. Hollenkamp and S. W. Donne, Electrochim. Acta, 2013, 104, 140-147.

56. W. Kohn and L. J. Sham, Phys. Rev., 1965, 140, A1133-A1138.

57. P. E. Blöchl, Physical Review B, 1994, 50, 17953-17979.

58. S. Grimme, J. Comput. Chem., 2006, 27, 1787-1799.

59. S. Grimme, J. Antony, S. Ehrlich and H. Krieg, J. Chem. Phys., 2010, 132, 154104. 